\title{
Selecting Suitable Sites for Mine Waste Dumps Using GIS Techniques at Goldfields, Damang Mine*
}

\author{
${ }^{1}$ H. A. Suleman and ${ }^{2}$ P. E. Baffoe \\ ${ }^{1}$ Goldfields Ghana Limited, Tarkwa, Ghana \\ ${ }^{2}$ University of Mines and Technology, P.O. Box 237, Tarkwa, Ghana
}

Suleman, H. A. and Baffoe, P. E. (2017), "Selecting Sites for Mine Waste Dumps Using GIS Techniques at Goldfields, Damang Mine", Ghana Mining Journal, Vol. 17, No. 1, pp. 9 - 17.

\begin{abstract}
The selection of optimal sites for mine waste dumps is a significant problem associated with surface mines operations. A number of factors such as financial, environmental and safety requirements must be simultaneously considered to avoid potential losses. This research used the ModelBuilder tool and several GIS spatial analyst tools to select suitable sites for mine waste dump. The weighted overlay technique was adopted by first determining the necessary criteria and constraints and subsequently developing attributes for each criterion. The criteria used were grouped into a binary category of suitable and unsuitable. A total area of $17.01 \mathrm{~km}^{2}$ was determined as suitable, while $66.10 \mathrm{~km}^{2}$ was classified as unsuitable after overlaying and weighting all the criteria. Out of the suitable areas, an area of $13.62 \mathrm{~km}^{2}$ consisting of 21 sites were determined as optimal. Applying further constraints, 2 out of the 21 optimal sites were determined as the best sites. A stepwise model has been developed using ModelBuilder for selecting an economic but effective site for dumping mine waste using suitable constraints and criteria. This has facilitated the production of suitability maps generated from the various datasets being used for mine waste dump site selection. The final output map that best fits the criteria and constraints can be used by decision makers to set out the areas suitable for mine waste dump sites on the mine concession. The model could be applied as the standard model for selecting sites for mine waste dumps, since there is no standard model available at the moment.
\end{abstract}

Keywords: ModelBuilder, GIS, Constraints, Waste Dumps, Weighted Overlay

\section{Introduction}

Mining operations involve the extraction of precious minerals in the form of ore from the earth for both commercial and non-commercial purposes. Most of the mineralised ores are embedded in the earth. Mining operations to exploit the ore are normally done either by underground or surface mining.

In surface mining operations, before the ore is mined, the overburden would have to be stripped to reach the ore. The stripped overburden is normally called waste material. Large volumes of waste materials are generated during the stripping of the overburden and mining in order to mine the precious ore. These waste materials often termed mine wastes (overburden, low mineral content or barren material) are then disposed into mine waste dumps. Also, during the processing of the mined ore, liquid waste in the form of tailings/slurry is generated which is dumped separately from the solid mine waste (Kumral and Dimitrakopoulos, 2008).

The manner in which the mine waste is managed is of major concern to the stakeholders of the mine, including mine planners, government officials, local communities, etc. This is because if the waste material is not handled properly it could cost a company several millions of dollars, considering the fact that the cost of handling waste material is almost half of the mining costs (Kumral and Dimitrakopoulos, 2008). Also, when the mining operation is completed, mined out areas and mine waste dumps need to be rehabilitated. Location analysis as part of rehabilitation planning is considered prior to the beginning of mining operations. Therefore, cost effective but efficient methods for the selection of optimal site (s) for waste dumps in the mine is thus of significant concern to management and stakeholders of surface mines (Zahl et al., 1992).

The major factors that are considered during the site selection process include; financial, environmental, geological, land-use and safety requirements. These factors are combined simultaneously to avoid potential losses. Some of the environmental factors are land, air and water pollution, forest destruction, etc. It costs mining companies millions of dollars to re-handle and transport mine wastes (Salomons and Fortner, 2008), thus affecting the financial sustainability of companies. The stability and ore richness of the dump site must also be considered during the mine planning and mine waste dump site designs.

Most mine waste dump storage systems are designed to minimise the effect on the environment due to acid rock drainage, surface water run-off, dust emissions and visual pollution. Modern mine 
waste management requires mine waste to be placed on specially prepared sites that satisfy all the major factors (Anon, 2001). Failure to include these factors or non-assessment of these factors during the early stages of the site selection procedure often results in severe negative implications (such as fines, mine closure, protests, relocation of dumps, environmental pollution, etc.). Most mining companies use different methods for selecting sites for dumping of waste. However there is no standard model which combines these constraints and factors for selecting sites for waste dump. The improved capabilities of information technology have brought about these possibilities (Parker and Raker, 1988).

In this research work, a suitable model for mine waste dump site selection was designed using the ModelBuilder and other analytical tools in ArcGIS 10.0 environment to select and map out suitable locations for dumping solid mine wastes taking into consideration the various limiting major factors.

\section{Resources and Methods Used}

\subsection{Study Area}

Damang is located approximately on latitude $5 \circ 30^{\prime}$ $\mathrm{N}$ to $5^{\circ} 48^{\prime}$ and longitude $2 \circ 14^{\prime} \mathrm{W}$ to $2 \circ 08^{\prime} \mathrm{W}$ and about $280 \mathrm{~km}$ west of the capital Accra. A trunk road of about $145 \mathrm{Km}$ links the mine to the Takoradi port on the south-eastern part of the Atlantic coast in the Western Region of Ghana (see Fig. 1). AGL mining lease covers an area of about $260.0 \mathrm{~km}^{2}$ and about $40 \mathrm{~km}$ to the north of Tarkwa with good access roads (Joseph, 2005).

The main Damang community was resettled on the Damang-Tarkwa road about $1.5 \mathrm{~km}$ from the mine. The village is connected to the national grid and has bores holes as well as pipe borne water supplied by the company. The main water source is from the Damang dam with the Ayaasu River serving as backup water supply. The company has its own backup power supply with a capacity of 17.5 Megawatts and an operating capacity of 14.5 Megawatts (Francis, 2007).

The Damang area is characterised by gently rolling hills with an extensive drainage networks including low-lying swamp areas having a maximum local topographic relief of approximately $80 \mathrm{~m}$. Typical of tropical climate zones, Damang temperatures average monthly between $21^{\circ} \mathrm{C}$ and $32^{\circ} \mathrm{C}$ as well as two distinct rainy seasons from March-July and September-November. The average rainfall near the site is about $2030 \mathrm{~mm}$.

\subsection{Data Collection}

The Garmin GPS 60CSx handheld GPS was employed for the collection of geographic data during field navigation. This was done to validate the other geographic datasets that were obtained from other sources.

\subsection{Rectification and Data Validation}

Rectification and data validation was done for a certain degree of accuracy and reliability to be attached to this data. In order to do this, ground truth surveys were conducted. During the ground truth surveys, the position of 30 features which were mainly road intersections, intersection of road with railway line and survey controls points were collected. The positions of these features were plotted on a base map consisting of the concession boundary, roads, railway lines and survey controls. The result of the validation process was a stack of consistent data or map files whose geographic positions had been rectified, verified and validated.

Since the datasets used were obtained from different sources, they were also in different coordinate systems. Therefore there was the need to transform them into a common UTM coordinate system. In doing this, 10 controls were identified and their positions obtained in both the local coordinate system and in UTM. The positions of these 10 controls were then plotted in both coordinate systems. The local coordinates were rectified into their respective UTM coordinates accordingly. A root mean square error of 0.03 was obtained during the rectification process.

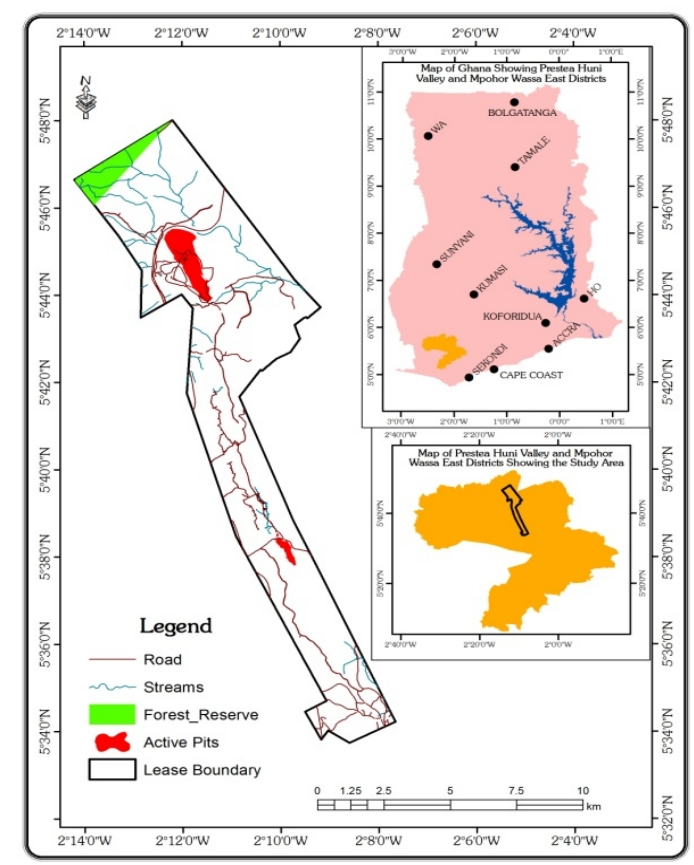

Fig. 1 Location of the Study Area 


\subsection{Selecting Sites for Mine Waste Dumps}

In this study, the Weighted Overlay method was employed. This methodology was first implemented by determining the necessary criteria and constraints and subsequently developing attributes for each of the criterion. The criteria that were selected were grouped into two categories of suitability or desirability, namely suitable and unsuitable. Table 1 shows the criteria adopted for this research. Weighted site selection analysis was used. In order to use weighted site selection there is a standard workflow that should be followed. This workflow usually begins with defining a problem or criteria such as locating some potential sites for a mine waste dump site. The next step is to gather data and create raster surfaces to be used in the analysis. This step is followed by reclassifying the layers, weighting them and then overlaying the output layers with background information such as a map of topography to see the best potential sites.

Table 1 Criteria used for the Grouping

\begin{tabular}{|c|c|l|}
\hline Criteria & Suitable & Unsuitable \\
\hline Pit & $50 \mathrm{~m}-500 \mathrm{~m}$ & $<50 \mathrm{~m},>500 \mathrm{~m}$ \\
\hline Ore-body & $100 \mathrm{~m}-500 \mathrm{~m}$ & $<100 \mathrm{~m},>500 \mathrm{~m}$ \\
\hline Road & $20 \mathrm{~m}-100 \mathrm{~m}$ & $<20 \mathrm{~m},>100 \mathrm{~m}$ \\
\hline Settlement & $>500 \mathrm{~m}$ & $<500 \mathrm{~m}$ \\
\hline $\begin{array}{c}\text { Water } \\
\text { bodies }\end{array}$ & $>200 \mathrm{~m}$ & $<200 \mathrm{~m}$ \\
\hline Utility & $>30 \mathrm{~m}$ & $<30 \mathrm{~m}$ \\
\hline Tectonic & $>1.6 \mathrm{~km}$ & $<1.6 \mathrm{~km}$ \\
\hline Forest & $>100 \mathrm{~m}$ & $<100 \mathrm{~m}$ \\
\hline Slope & $<15 \%$ & $>15 \%$ \\
\hline
\end{tabular}

\subsection{Creation of the Model}

After the criteria were determined, a model was created for the selection of the suitable site. To ensure easy update and usage of the model, a toolbox was created to contain the model. After this, the model was created and various environmental settings were defined for the model. The specific properties included in the process are presented in the following subsections.

\subsubsection{Processing Extent}

In this situation the boundary of the concession was used as the processing extent. The model was stored as relative path names and not absolute path. Doing this set all sources path referenced by the tool as relative to the location of the toolbox. Therefore the model could be transferred from one computer to another without repairing the dataset used.
Workspace: two different personal geodatabases were created, one for the input (current workspace) and the other for the results (scratch workspace).

Cell Size: the cell size of the digital elevation model (DEM) was used. This was because the DEM happens to have had the largest cell size among all the dataset.

Mask: the boundary of the concession was used.

The model was built by stringing tools together in a ModelBuilder. Once the model was created, it was easy to experiment with parameter values, use different input data, run the model over and over again and share it with others.

After creating the model and subsequently defining its environment settings, it was ready to be used in processing the project data to locate the suitable site for the new mine waste dump. The following dataset were derived from the project data.

\subsubsection{Deriving Datasets}

Since the area is generally undulating with several mountains, there was the need to find areas which are relatively flat on which to build, therefore the slope of the land was considered. Additionally, the new site needed to be a low laying area since it will be filled such that its height flashes that of the surrounding mountain in order to maintain the aesthetic view of the area without causing any visual pollution. Using the DEM as input, slope dataset was derived using degree as the measurement output.

\subsubsection{Deriving Distances}

Apart from the DEM (slope) data, distances were created for the datasets. This was necessary because, the new site should be of a certain distance from those dataset. In deriving these dataset, the Euclidean Distance tools, which is a straight line distance was applied on each of those dataset. Thus, a straight-line distance was calculated from the pits, ore-body, road and rail, settlements, water, utility, tectonic and forest datasets.

During the process of deriving the various datasets, all the input data were defined as model parameters. Doing this assists other users to easily distinguish input dataset which can be changed from output dataset. Additionally, all output datasets were set such that they were automatically added to the map display anytime they are run. After performing these tasks, the datasets (Slope and Euclidean Distance) were examined individually to derive their respectively dataset. 
Fig. 2 shows a sample of how the model looked like after it was created and the datasets were derived. After the model was ran, the datasets that were derived were added to the map documents as layer. The added layers were subsequently examined individually to make sure that there was no error during the derivation of the various datasets.

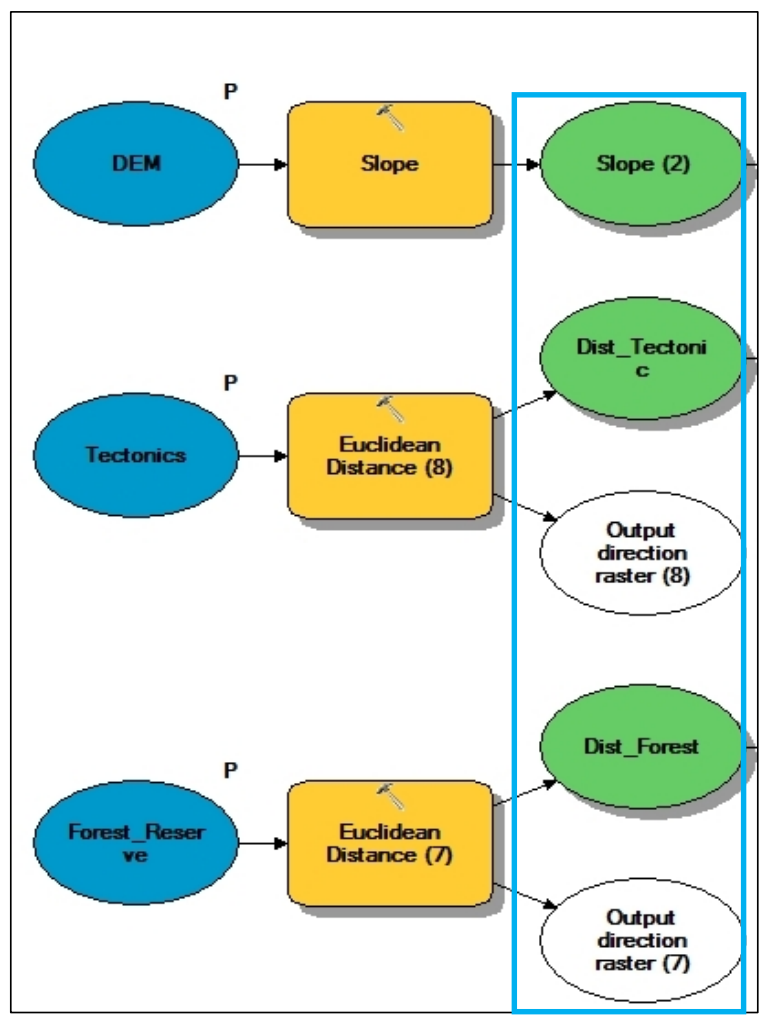

Fig. 2 The Model for Deriving the Datasets

\subsubsection{Reclassifying Datasets}

Deriving datasets, such as distance to pits, is the first step when building a suitable model. Each of the cells in the study area now has a value for each input criteria including slope, distance to pits, distance to ore-body, distance to road, distance to river/stream, distance to settlements, distance to utility, distance to forest reserve and distance to tectonic zones such as fault, and fractures. At this stage it was practically impossible to combine the derived datasets. For instance, combining a cell value in which slope is $10^{\circ}$ with a cell value for distance to pits equals $700 \mathrm{~m}$ to get a meaningful answer that can be compared to other locations is impossible. Hence, there was the need for reclassification of each of the individual dataset.

Thus, to combine datasets, there is the need to first set all the individual datasets on a common measurement scale such as 1 to 5 . This common measurement scale is what determines how suitable a particular location (each cell) is for siting the new waste dump. Higher values indicate more suitable locations, while lower values indicate less suitable or unsuitable area. For this particular study, all the datasets were reclassified into two classes (1 and 2), 1 for unsuitable areas and 2 for suitable areas.

The values in the datasets derived in the previous method or step are all floating-points, continuous datasets, categorised into ranges and needed to be classified so that each range of values is assigned one discrete integer value such as 1 or 2 according to the measurement scale. This is because the inputs of the Weighted Overlay which would be used in the next step must contain discrete integer values. The derived datasets were reclassified into two classes. Fig. 3 shows how the model looked like after the derived datasets were reclassified.

\subsubsection{Weighting and Combining Datasets}

After the derived datasets were classified into a common measurement scale, it was possible to combine all the datasets and assign weights to them. Using the weighted overlay tool, all the datasets were combined to obtain a suitable map. Since all the datasets were of different importance, there was the need to attach a degree of influence to each of them. Therefore all the reclassified datasets were weighted and assigned a percentage influence to each of them.

The weights were determined after a thorough literature review and desktop study. Furthermore, expert mine planners who have been involve in the design and implementation of waste dumps were also consulted to determine weights for the datasets. Table 2 shows the weights and percentage of influence that were assigned to the individual datasets. During the usage of the weighted overlay tool, an evaluation scale was set. Since a measurement scale of 1 to 2 was used during the reclassification of the datasets, the evaluation was done using set from 1 to 2 by 1 . This will avoid having to update the scale values after adding the input dataset. The weighted overlay resulted in the production of a suitability map showing both the suitable and unsuitable area.

Fig. 4 shows how the model was used to select the optimal areas.

Table 2 Assigned Weights

\begin{tabular}{|c|c|c|}
\hline Criteria & Weights & $\begin{array}{c}\text { Percentage of } \\
\text { Influence }\end{array}$ \\
\hline Pit & 0.17 & $17 \%$ \\
\hline Ore-body & 0.19 & $19 \%$ \\
\hline Road & 0.15 & $15 \%$ \\
\hline Settlement & 0.13 & $13 \%$ \\
\hline Water bodies & 0.11 & $11 \%$ \\
\hline Utility & 0.07 & $7 \%$ \\
\hline Tectonic & 0.05 & $5 \%$ \\
\hline Forest & 0.09 & $9 \%$ \\
\hline Slope & 0.04 & $4 \%$ \\
\hline
\end{tabular}




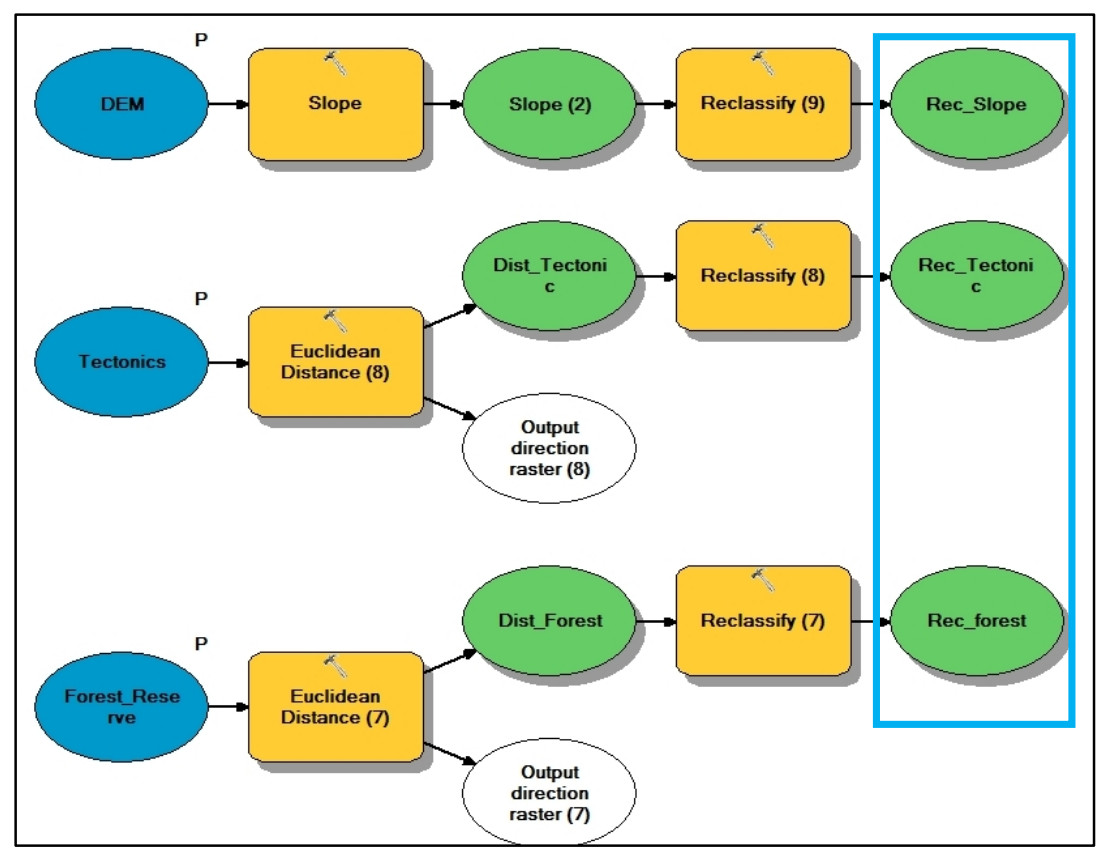

Fig. 3 Model after Reclassifying the Derived Datasets

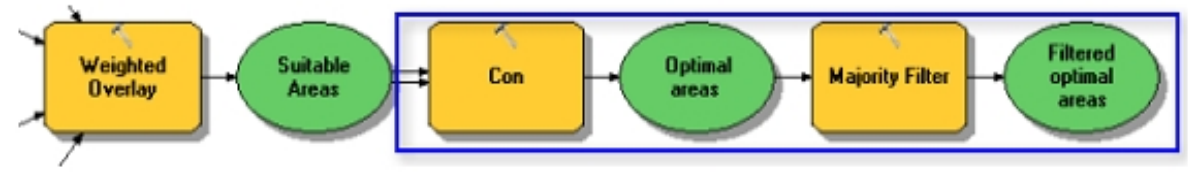

Fig. 4 Model for the Selection of Optimal Area

The conditional tool was first used to select only the suitable areas (that is areas with a cell value of 2). After examining the results of the condition tools it was observed that, many single cells were representing suitable locations. Therefore the result was filtered to clean-up, removing all the small areas. Majority Filter was used specifying 8 (a 3by-3 cell window) as the number of neighbouring cells to use in the kernel of the filter to remove all the small areas.

The filtered areas raster was converted to vector layer so that the minimum size constraint could be applied to select the optimal areas. The area of each of the elements in the vector layer was determined and added as attribute. Based on the area attribute, a query was created to selected areas which are equal to or greater than $10800 \mathrm{~m}^{2}$.

It was observed that some locations were determined as the optimal areas, therefore there was the need to streamline this number to obtain the best site. The tailings dam layer was applied as a constraint to reduce the number. Additionally, optimal areas which were not intersecting with a road were taken out since nearness to road is essential in this project. Two site were selected as the best site for the new waste dumps, one the north and the other at the south.

\subsubsection{Validation of Model}

After determining both the optimal and the best sites, there was the need to validate the result to ensure that the model that was created was free from errors. In doing this validation exercise, locations of existing waste dumps were plotted and superimposed on the layer showing the optimal site. After the superimposition, intersecting places were determined. It was observed that about $86 \%$ of current and old waste dumps were intersecting with the locations that were determined as optimal area. Out of 14 current and old waste dumps, 12 were intersecting with the optimal areas as determined from the modelling process.

\section{Results and Discussion}

The results obtained from the research are presented in the following sub-sections. The results of each of the stages have been presented.

\subsection{Results of Deriving Datasets}

To effectively manage, process, and integrate massive point collections of the $3 \mathrm{D}$ data that result from collecting high-resolution elevation observations using remote sensing, and other technologies, there is the need to derive some 
datasets to help in achieving desired results. The following are the datasets derived from the spatial analysis of the data.

Land use /cover data and ground truth data were used to derived the various datasets.

\subsection{Results of Reclassifying the Datasets}

In order to identify the areas suitable for the mine waste disposal, reclassification was carried out. Fig. 5 shows the results of the reclassification. Reclassification involves the reassignment of the values of an existing map as a function of its initial value, position, size, shape or contiguity of the spatial configuration associated with each map category. In this paper, the reclassification tools were used to reclassify or change cell values to alternative values using a variety of methods.

Groups of values were applied to alternative fields to reclass based on the criteria set. The tools are designed to allow for easy change of many values on an input raster to desired, specified, or alternative values.

All reclassification methods were applied to each cell within a zone. That is, when applying an alternative value to an existing value, all the reclassification methods apply the alternative value to each cell of the original zone. The reclassify data included: distance to; orebody, forest reserve, pits and roads, settlement, water bodies, utility lines; slope.
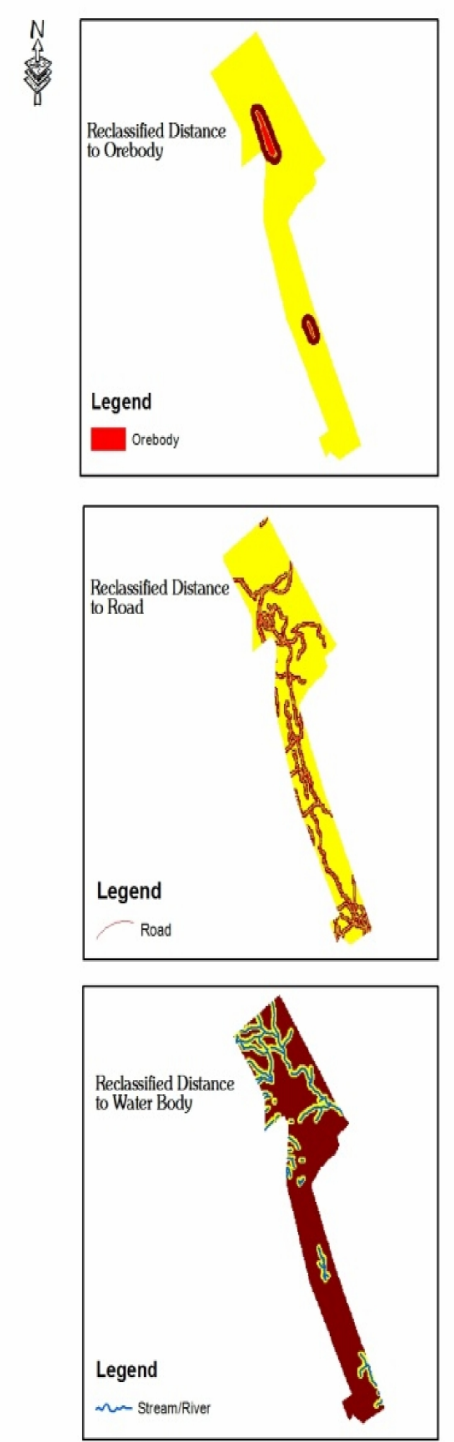
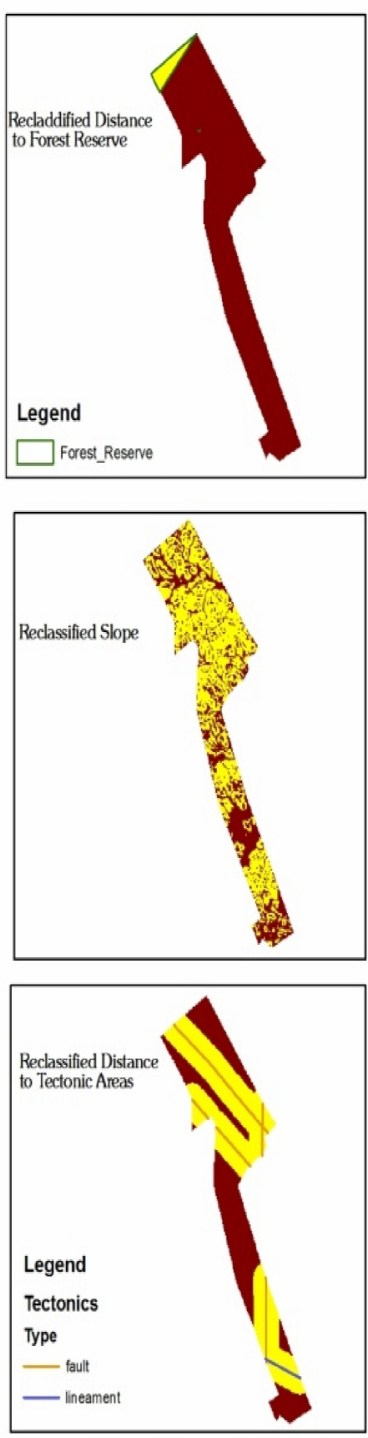
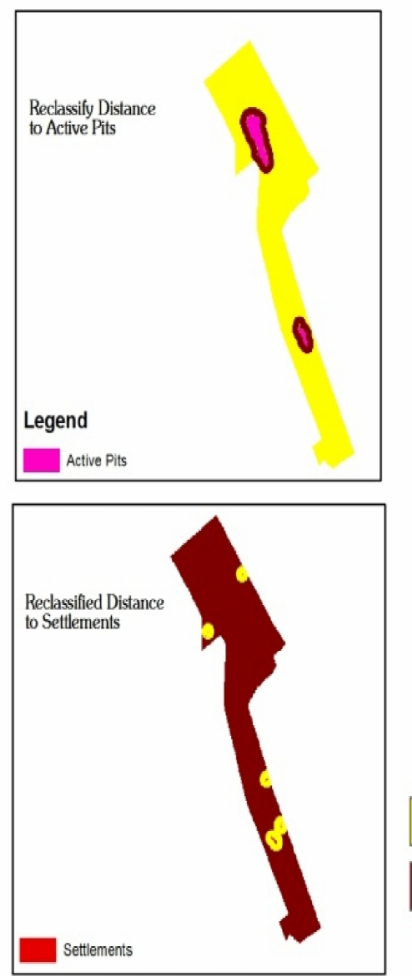

LEGEND

Unsuitable

Suitable

Fig. 5 Reclassifying Datasets 


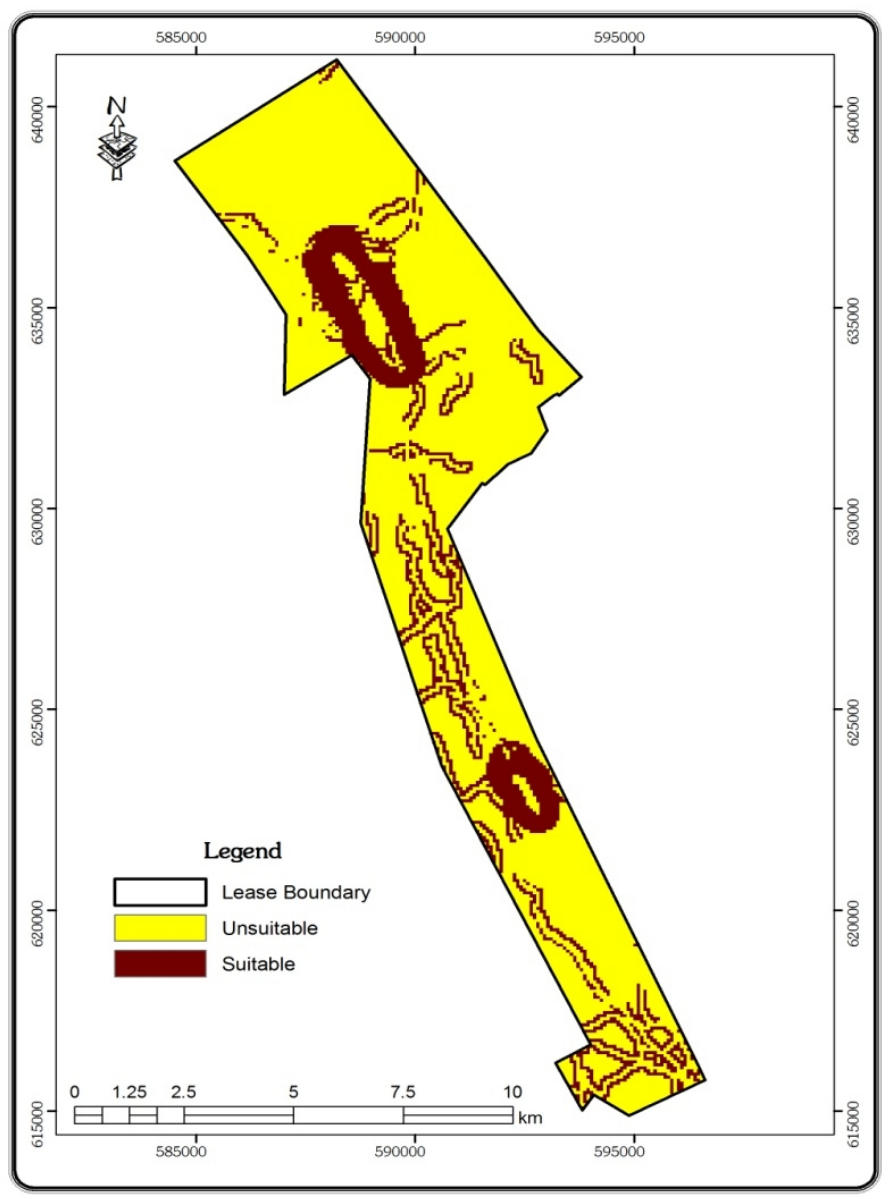

Fig. 6 Weighting and Combining Datasets

\subsection{Results of Weighting and Combining Datasets}

Weights were assigned to the individual layers of the datasets for the analysis. The result is as shown in Fig. 6. The derived datasets and land use are combined and weighted to find the most suitable sites for the mine waste disposal. The values of the derived datasets have all been reclassified to a common measurement scale (more suitable cells have higher values). Values representing areas of water bodies and wetlands will be restricted. Areas with steep slope values are less also restricted so as to exclude their values. If all datasets were equally important, they could simply be combined, giving each equal influence; however, they are not of equal weights hence, weight are assigned to each inputs. The higher the weight, the more influence a particular input will have in the suitability model.

After weighting and combining the datasets, the areas of suitability were extracted from the datasets and the results were tabulated in Table 3 . The results showed that the unsuitable areas was 66.10 $\mathrm{km}^{2}$ representing $79.53 \%$. Moreover, the extracted area for suitable areas covered $17.01 \mathrm{~km}^{2}$, this also representing $20.47 \%$ as shown in the Table below.
Table 3 Areas of Suitability

\begin{tabular}{|l|c|c|}
\hline \multirow{2}{*}{ Suitability } & \multicolumn{2}{|c|}{ Area } \\
\cline { 2 - 3 } & Km $^{2}$ & $\%$ \\
\hline Unsuitable & 66.1 & 79.53 \\
\hline Suitable & 17.01 & 20.47 \\
\hline Total & $\mathbf{8 3 . 1 1}$ & $\mathbf{1 0 0 . 0 0}$ \\
\hline
\end{tabular}

\subsection{Results of Selecting Optimal Sites}

A total of 21 sites were selected as optimal sites occupying an area of $13.62 \mathrm{~km}^{2}$. Fig. 7 shows the results obtained for optimal sites and selected for consideration.

\subsection{Results of the Final Sites Selection}

Out of the 21 optimal sites, two were determined as the best sites. These are all situated within the peripheral of the two main active pits. This is represented in Fig. 8. The green colour representing best site labelled as the final sites. The red colour also represents the active pits. 


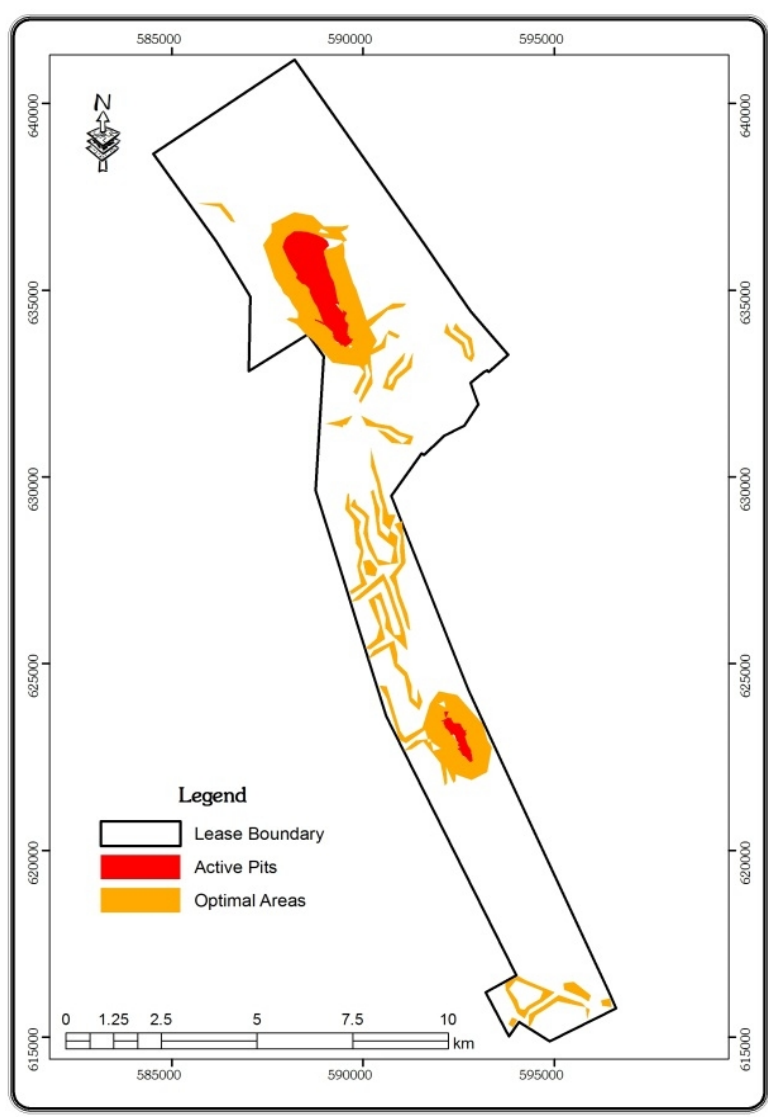

Fig. 7 Selecting Optimal Site

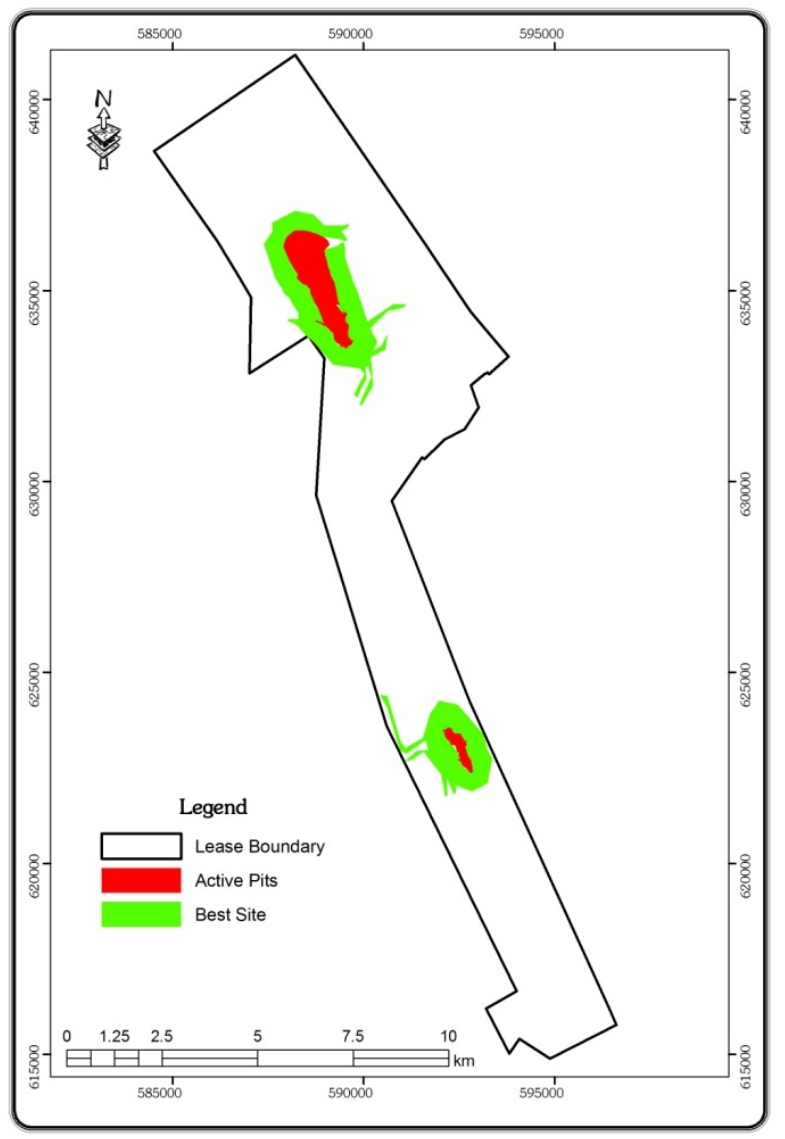

Fig. 8 Selected Final Sites

\subsection{Validation of the Model}

The final model was validated and an accuracy of $86 \%$ was achieved. The results for the validation of the model are presented in Fig. 9. The active pits are delineated from the waste dump area and subsequently from the optimal areas. These are differentiated from each other by the respective colours.

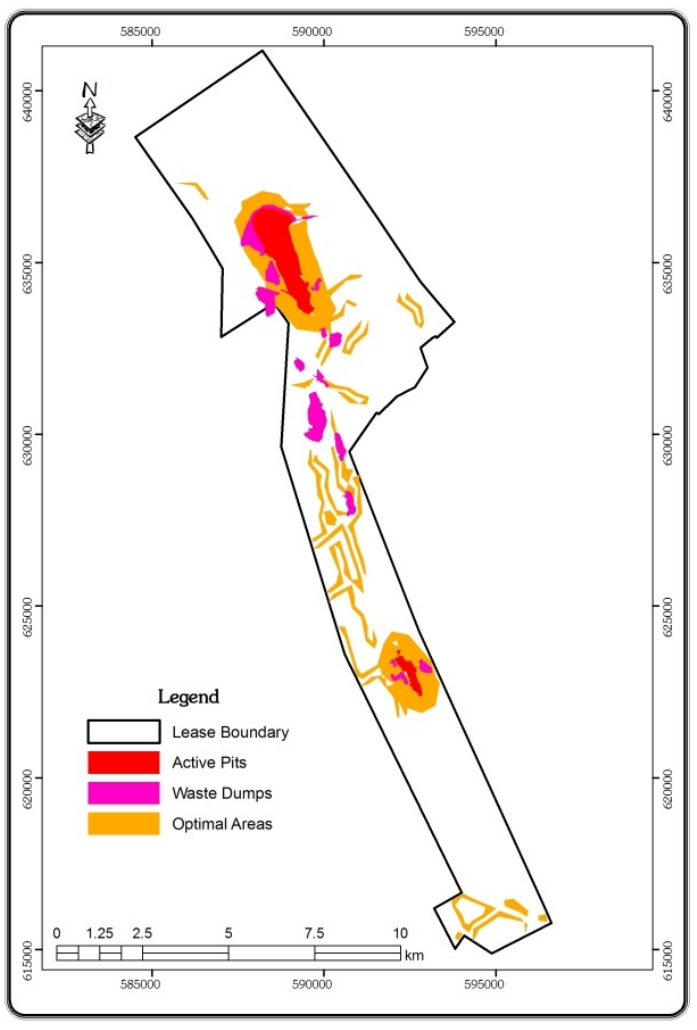

Fig. 9 Results after Validating the Model

\subsection{Discussions}

From the suitability map the areas suitable for mine waste dump sites were spatially analysed and selected. This was done by creation of eucleanian distance for all the datasets and standardization to bring all data to a common scale. Combination of all the criteria also resulted in the weighted map. By considering minimum area based on the requirements for the selection of mine waste dump site, an optimal map was spatially generated. From the optimal map generated, distances from the pits to the waste dump sites were determined and those with minimum distance to the pits were selected and this resulted in the identification of the optimal locations. Validation of the optimal sites was done by superimposing some collected datasets and the existing pits on the map generated. The result proves $86 \%$ accuracy. The output of the optimal location map can be used by decision makers to set out the areas suitable for mine waste dump sites on the mine concession. 


\section{Conclusion}

A step-wise model has been developed using ModelBuilder in ArcGIS software suite for selecting suitable site for dumping mine waste. The employed constraints and criteria for site selection enabled the selection of optimal sites for dumping of waste. This has facilitated the production of suitability maps for mine waste dump site selection.

Though the model designed is for solid rock mine waste from mining, it can also be used to select sites for both liquid and domestic wastes by varying parameters and conditions. In addition, the research has also provided guidelines for future mine waste dump site selection.

This research has provided a suitable model for mine waste dump site selection for AGL as such the company should make it a working document to benefit from the research.

The research has helped to reveal that, apart from its site selection capabilities, GIS could also be employed in other areas of mining such as mine planning, survey works, geotechnical monitoring of pit walls etc.

There is the need for companies to consider alternative routes to its dump sites as one or limited routes deprives the company of alternative cost effective routes to dump sites.

\section{References}

Anon. (2001), "Management of Mining, Quarrying and Ore-processing and waste in the European Union", www.glogalmining.com, Accessed: November 20, 2014.

Joseph, D. M. (2005), "Geostatistical Evaluation of Mineral Deposit: A Case Study at Goldfields Ghana Limited, Damang Mine", MSc Thesis, University of Mines and Technology, Tarkwa, $121 \mathrm{pp}$.

Kumral, M. and Dimitrakopoulos, R. (2008), "Selection of waste dump sites using a Tabu Search Algorithm", The Journal of the Southern African Institute of Mining and Metallurgy, Vol. 108, pp. 1-2.

Mensah, F. (2007), "Integrating Global Positioning Systems and Geographic Information Systems in Mine Waste disposal: The Case of Goldfields Ghana Limited", MSc Thesis, University of Mines and Technology, Tarkwa, $114 \mathrm{pp}$.

Packer, K. and Raker, D. S. (1988), Computer Mapping in Geographic Information Systems for Market Research, $3^{\text {rd }}$ edition, National Graphics Association, London, UK, pp. 92.

Salomons, W. and Forstner, U. (2008), Environmental management of solid waste:
Dredged material and mine tailings, SpringerVerlag Publishers, New York, USA, 665 pp

Zahl, E. G., Biggs, F., Boidt, C. M. K., Connolly, R. E., Gertsch, L., Lamberth, R. H., Stewart, B. M. and Vickery, J. D. (1992), Waste Disposal and Contamination Control, SME Mining Engineering Handbook, $2^{\text {nd }}$ edition, Vol. 1, USA, pp.1170-1178.

\section{Authors}

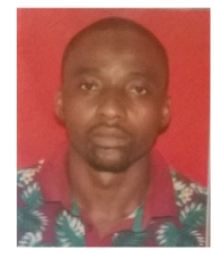

Hamid Adams Soleman holds MSc and BSc degrees from the Geomatic Engineering Department, UMaT, Tarkwa. And he has been working in the mines for the past six years as a Geomatic Engineer.

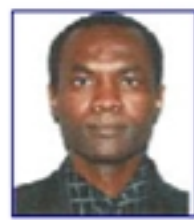

P. E. Baffoe holds MSc (Survey) from Moscow, and he is a Senior Lecturer at the Department of Geomatic Engineering, University of Mines and Technology. His research interests include application of GIS in Environmental Issues, 3D Modelling, Digital Photogrammetry and Mine Surveying, Land Information Systems and Mine Surveying. 